\title{
In-site transportation of concrete mix: new typology of methods, potential and fields of modern mechanization means' rational application
}

\author{
Sergey Osmanov, *, \\ Don State Technical University, 344000, Rostov-on-Don, Russia
}

\begin{abstract}
The main structural material in construction industry is concrete. The article discusses the features of modern methods and means of in-site transportation of the mixture that subsequently forms it and, in particular, its supply to the concreting blocks of monolithic structures. The requirements of Russian norms for this process implementation, as well as the world practice of using the machines, equipment and devices intended for this, are analyzed. A new typology of methods for in-site transportation of concrete mixture is proposed, based on the differences between them in the type and resource intensity of the main moving action. Generalized, systematized and brought to the applied form information about the productivity and parameters of the mechanization corresponding means working zones, as well as the mixture technological properties influence on the possibility of their use. The data obtained made it possible to clarify the rational use areas of the main types of such technology and to reveal the contradictions associated with this. In general, the research results presented in the article facilitate the identification of shortcomings and promising directions for improving the considered competing methods and technical means, as well as justification of the choice between them.
\end{abstract}

\section{Introduction}

In modern construction, the transportation of ready-to-use concrete mixture (hereinafter, mixtures on dense aggregates are considered) are divided into external (from the concrete plant to the construction site) and on-site. The latter, on the one hand, may include the unloading of distribution equipment and (or) other on-site vehicles into containers. On the other hand, the most resource-consuming, technically difficult, and also the only mandatory component of the in-site transportation of the mixture is its supply to the location place in the concreting blocks of monolithic structures [1-3]. The share of this process in the cost and labor intensity of their construction, respectively, averages about 10 and 25\% [2]. Moreover, in some cases, the financial costs of supplying the mixture reach $50 \%$ of its selling price. This

\footnotetext{
* Corresponding author: osmanov.tsp@ya.ru
} 
is the case, for example, with small amounts of work and (or) concreting of hard-to-reach structures inside structures under construction or reconstructed. In any case, not only the number of consumed resources, but also the quality of concrete work largely depends on how well the methods and means of supplying the concrete mixture to the place of laying are chosen [1, 3-5].

For other components of the mixture in-site transportation, there is no problem of such a choice. Unloading is carried out by means of delivery to the construction site, reloading - by the estorage bins. By the way, both those and others in a number of cases can be used as a means of supply, and such options for mechanization should be given preference as the most profitable $[4,5]$. Therefore, speaking about the rational mechanization of concreting, in-site transportation will be considered only in terms of concrete supply.

In Russia, the main regulatory documents governing this process are GOST 7473-2010, $\mathrm{BC} 70.13330 .2012$ and $\mathrm{BC} 435.1325800 .2018$. In fact, their respective requirements are reduced to the need to preserve the design properties, composition and volume of the mixture during transportation. However, it is easy to see that the instructions containing permissible conditions for the use of the means of such transportation are not of a systemic nature. They are given only for some of such means, and this information is not enough even for a preliminary selection of alternative mechanization options in order to further analyze their effectiveness. Therefore, it is not surprising that the data collected by the author on the practice of using concrete delivery means (Fig. 1) looks as if such an analysis, when it is necessary, is often not carried out.

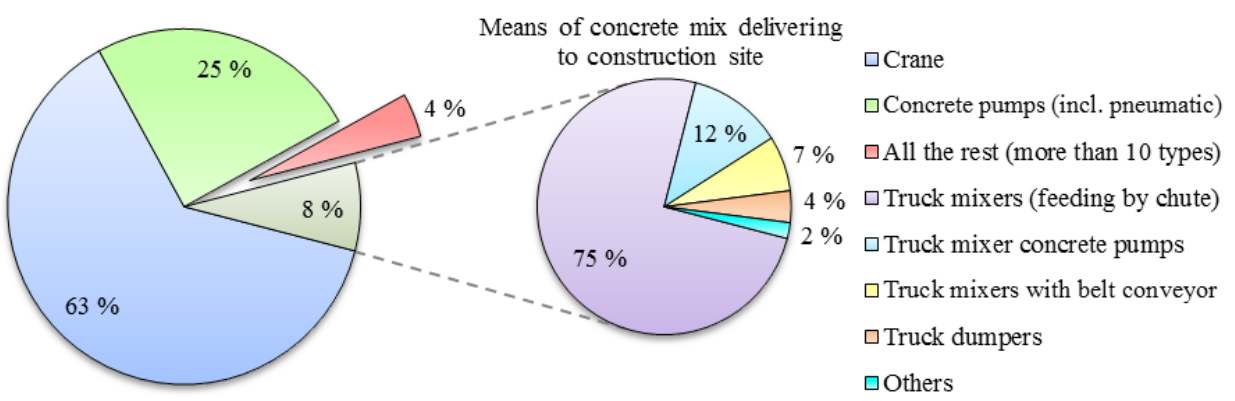

Fig. 1. Approximate distribution of mechanization means by volumes of concrete feeding while constructing the monolithic structures in Russia from 2015 till 2020

This problem is the least typical for hydraulic engineering, the norms of which have been developed additionally in terms of the issues under consideration (BC 357.1325800.2017). But no matter what scale it has, the justification of the options choice for mechanization of concrete works in itself is a difficult multifactorial task $[1,2,6]$ in modern conditions, in addition, complicated by a number of circumstances. On the one hand, there are no effective and convenient methods for such a choice that would optimally take into account the combined influence of the external and internal factors. On the other hand, the information on the possibilities and areas of such options' rational use contained in the scientific and reference literature is very outdated and is incomplete, inconsistent and poorly comparable. It seems that both one and the other are partly due to the fact that there is still no clear practice-oriented typology of methods for in-site concrete mixture transportation. All this, unfortunately, creates erroneous vectors for the appropriate technologies' development [7].

The analysis of the contractors work in Rostov-on-Don shows that the contradiction, suggested by the presented diagram, between the variety of known means for supplying concrete mix and the actual practice of their application objectively exists. The purpose of the research carried out by the author is to create tools that give an opportunity to correct this by 
providing the possibility of a qualitative justification for the choice of options for the concrete work mechanization within the framework of ordinary organizational and technological design. One of the current tasks of this study is to understand the depth of this contradiction, i.e., to understand how the practice of using modern concrete transport vehicles is consistent with their capabilities, and, if necessary, to propose the adjustments to the existing approaches in this area.

\section{Analytical framework}

The capabilities of the concrete mix in-site transportation means largely depend on the impacts' characteristics exerted on it and causing it to move. This is also applied to the preservation of the design characteristics of the mixture (for example, the degree of its homogeneity), and the geometry of the possible working zones of such means, and their productivity, and the required technological properties of the mixture itself. Concrete transport vehicles that are similar in nature to the displacement effect, have similar capabilities. However, the features of these effects are determined not so much by means as by the methods of transportation to which these means belong. It has been established that each of these methods is based on the use of 1 to 3 types of such influences (there are 4 of them in total), and if there are several of them, then one is always the main one. One of the main criteria for the optimal choice of options for the mechanization of concrete (as well as any other) work is the amount of possible saving of labor, material, technical and energy resources $[1,6,8]$. Displacement impacts can be appropriately ranked according to their resource intensity levels, and in the same order for all three types of resources. Taking into account these considerations, put by the author as the basis for a new (and at the same time, the first applied) typology of methods for the concrete mixture in-site transportation (Fig. 2), seems to be very useful in preliminary justification of the appropriate design solutions' choice.

It is easy to see that if at the first typological level (it is limited by the dotted line) the main influences are taken into account, then at the second and third - the options for their implementation, including those in combination with a different kind of influences. Directly, the methods of transportation in this case can be correlated with each other only in terms of energy intensity, and at the first level, although this is not indicated, in ascending order everything is in the same order (I - IV). However, the selected indicator, if understood globally, can partly be an alternative to both specific labor costs and specific financial costs for material and technical support. A direct comparison by them, in fact, would not be so universal, since it would give an ambiguous result, true only for certain objects and construction conditions.

The presented typology reinforces the contradiction noted earlier. So, it clearly shows that the most resource-intensive displacement effects are realized, nevertheless, by the most frequently used means of concrete mixture intra-site transportation (cranes and concrete pumps), although it is obvious that in the end this cannot but have a negative effect on their economic efficiency. Conversely, transportation means that implement the least resource-intensive impacts (gravitational and inertial) are extremely rarely used. On the whole, in this sense, a smaller part of the machines, equipment and fixtures studied is overestimated, and a larger part is underestimated. To find out to what extent this is justified by their basic operational characteristics, the author has carried out a corresponding thorough analysis of modern samples of concrete transport equipment and the effectiveness of their use at industrial and civil construction sites in Russia, China, the United States, Western Europe and the Middle East. The following most versatile such characteristics were selected: the geometric parameters of the working zones, the actual productivity and workability of an 
efficiently transported concrete mixture. We took into account mobile mixes with aggregate size up to $40 \mathrm{~mm}$ due to their greatest distribution in construction.

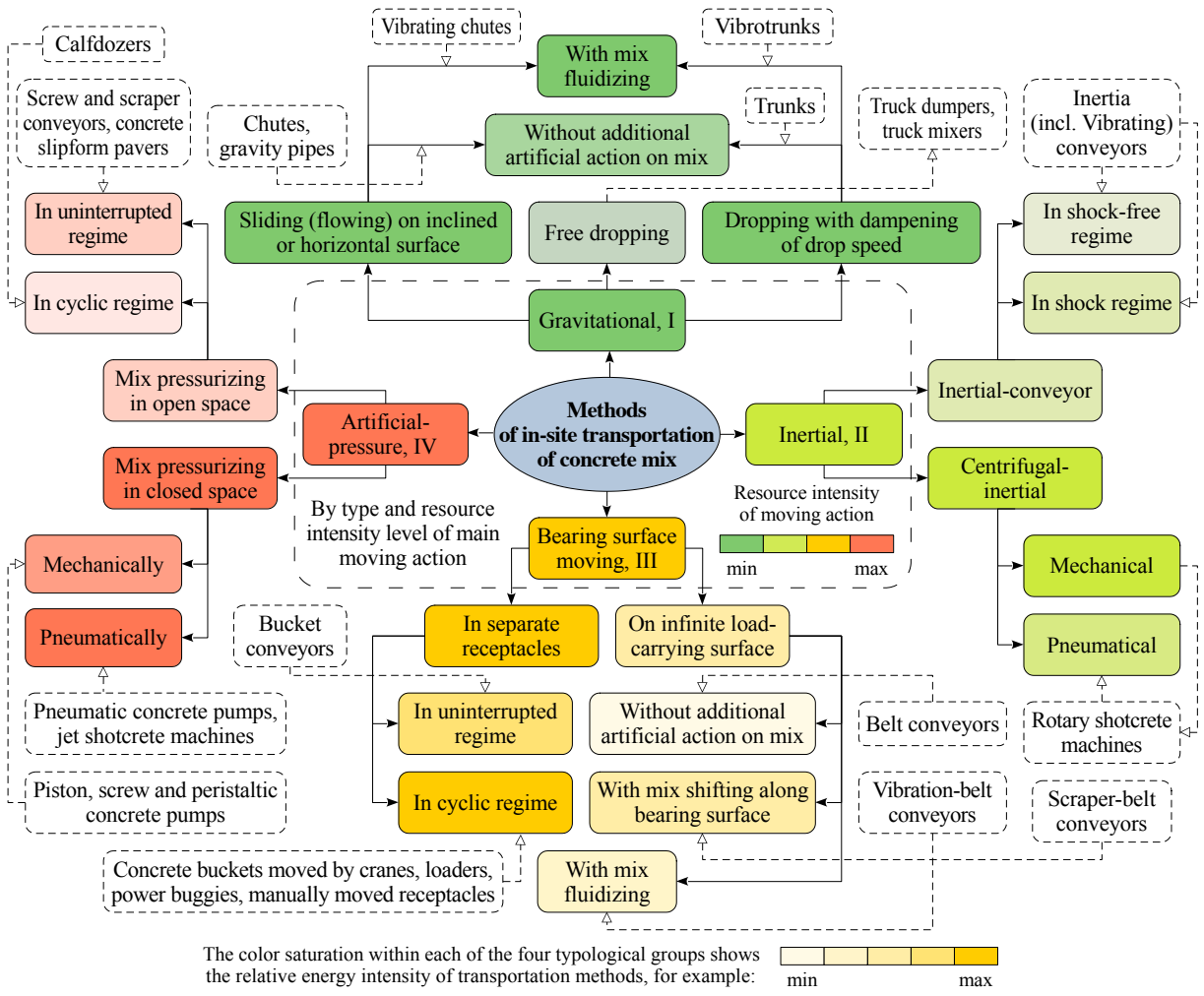

Fig. 2. Proposed typology of methods for concrete mix in-site transportation

The theoretical performance for advertising purposes, even in the data sheets of the considered means of mechanization, is often greatly overestimated, and therefore is not very informative $[9,10]$ when justifying their choice. It is usually unattainable even in ideal production conditions, at least due to the limitations on the speed of unloading and receiving the mixture by means of its delivery to the object and supply to the place of laying, respectively. These restrictions depend on the design features and schemes of this technique joint operation $[5,11]$. In addition, it was found that even at ultra-high rates of concreting, the coefficient of its use in time does not exceed 0.85. A detailed account of general and specific similar inevitable amendments helped to correct the theoretical values of the concrete transport vehicles investigated types productivity to the possible actual values of real scientific and practical interest.

For the numerical expression of the concrete mixture workability, we used the indicator of mobility with respect to the draft of a normal cone (GOST 10181-2014), although it weakly reflects the mixture rheology [12], nevertheless, it serves as a kind of integral reference point for its transportability by one means or another. However, to varying degrees for them, this guideline is not exhaustive, due to the difference in the influence of a number of other mixture characteristics on its tendency to form congestion along the route due to stratification. The volume and depth of the known experimental studies of this influence are extremely unevenly distributed among the types of concrete transport equipment. Therefore, it was taken into account by the author indirectly by ranking such species according to the requirements severity for the mixture non-segregation. 


\section{Results and discussion}

In the course of generalization and systematization of information about the concrete mixture in-site transportation modern means possibilities, it was also possible to clarify the areas of rational use of their main varieties, which, one way or another, made it possible to judge the practical significance degree of these possibilities. The results obtained (Fig. 3 and 4) can be used in building organizational and technological design as a tool for systematic assessment of the competing mechanization options' effectiveness.

The areas of concrete vehicles application are presented within the framework of their basic characteristics taken into account in the study. The areas of possible application satisfy a variety of situations (except for emergencies), when these means, working in a regular mode, can, in principle, be effective, i.e., to ensure the minimum technical and economic indicators of the concreting process, sufficient for practical purposes (including in terms of preserving the properties of the transported mixture), which, under certain conditions, would make it possible to put the necessary solutions into the project. Within the specified limits, for these areas, the restrictions on the high cost, complexity and labor intensity of operation, the amount of information about its experience, the stability of work in a changing production environment and other potential markers of a sharp decline in the competitiveness of the corresponding options and means of mechanization have been removed. The areas of rational application, on the contrary, satisfy the conditions of a consistently high competitiveness of these funds, when they cannot be rejected when choosing the solutions for mechanization without a technical and economic comparison with alternative means.

The boundaries of the considered equipment working areas (Fig. 3) take into account the possibility of concrete supply along a "chain" of several mechanization means of the same type (including those located in a cascade), if this scheme of work is typical for them. The number of stationary concrete pumps in such a "chain" is limited to two, and the length of individual vibrating trays, inertial and adjustable belt conveyors is taken equal to 4-6, 6 and 9-25 m, respectively. This scheme is inapplicable to cranes and concrete mixer trucks (regardless of the equipment), and when using concrete pumps and self-propelled concrete pavers, it is justified only in extreme emergency conditions, for example, when erecting protective structures in the course of eliminating the consequences of radiation accidents at APS [5], as it was in the USSR (1986) and Japan (2011).

The ranges of the required concrete mix flow and the actual performance (Fig. 4), related to cranes, take into account their operation with buckets with a capacity of up to $3 \mathrm{~m} 3$. With regard to inertial conveyors of the author's design [13], the presented diagram is valid when operating in effective (linked to the properties of the transported mixture) modes established by the results of previous studies [14] and, as it turned out [15], that do not negatively affect the homogeneity of the mixture itself nor on the uniformity in strength of the structures formed from it. The working body of these installations is a tray with an adjustable angle of inclination, asymmetrically oscillating along its axis with a high amplitude (25-95 mm) and low frequency (90-255 min-1). The author has developed a number of constructive modifications of such conveyors, both in a mobile version and in hinged ones as distributing equipment for concrete mixer trucks. 


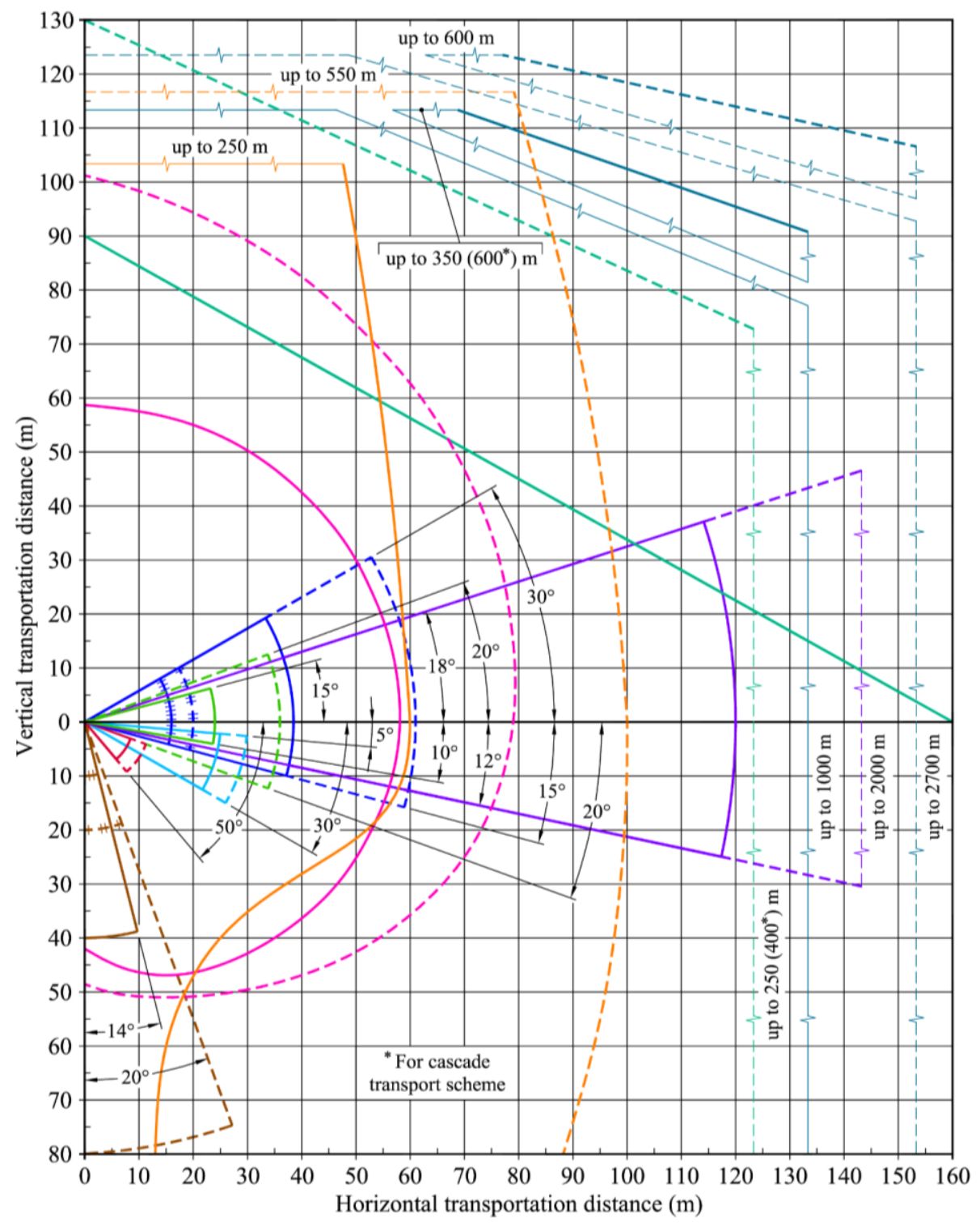

$\overline{---}$ Chutes $\overline{---}$ Vibrating chutes $\overline{---}$ Inertia conveyors of the author's design $\quad$ \#+m+ Sectional trunks $\overline{---}$ Sectional vibrotrunks $\overline{---}$ Stationary, trailer and self-propelled piston (hydraulic) concrete pumps $\overline{---}$ Stationary and trailer screw and pneumatic concrete pumps $\quad$ \#elt conveyors of truck mixers $\overline{---}$ Belt conveyors of self-propelled concrete pavers $=$ Stationary and adjustable sectional belt conveyors $\overline{---}$ Truck-mounted piston (hydraulic) concrete pumps $\overline{---}$ Cranes

Fig. 3. Working zones boundaries of modern means for in-site transportation of concrete mix: potential and rational application (dotted und solid lines respectively) 


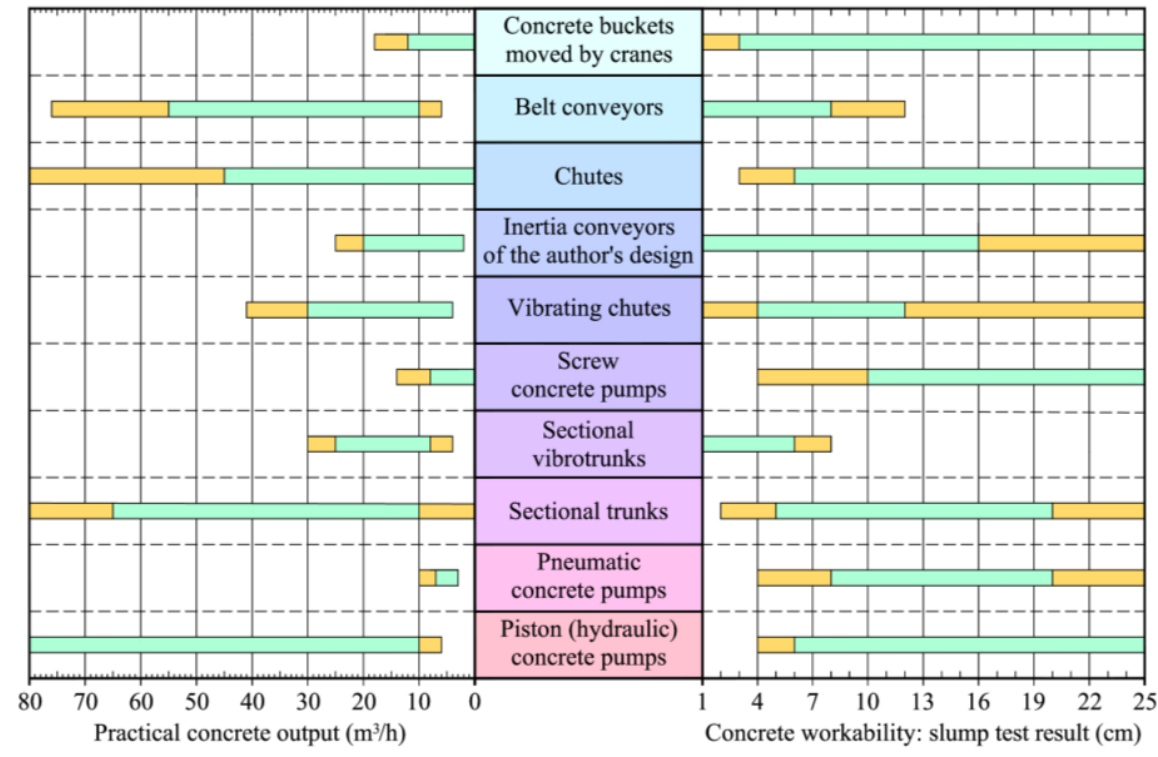

$\square$ Potential

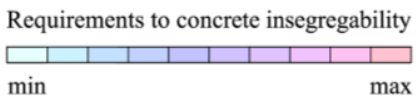

Fig. 4. Practical output and requirements to technological properties of concrete mix for modern means of its in-site transportation: potential and rational application

It was found that if in the operational documentation the performance of belt conveyors and reciprocating concrete pumps is most often overestimated (due to their high cost and high competition between manufacturers), then in the scientific and reference literature the same is observed in relation to pneumatic concrete pumps (due to the obvious unevenness of their rates. displacement in different countries by pumps with a hydraulic drive in the segment of small-scale mechanization). Therefore, the BC 70.13330.2012 position on the expediency of using pneumatic transport with an intensity of concrete work not less $6 \mathrm{~m} 3 / \mathrm{h}$ (in the absence of constraint in the conditions of their production and in the presence of access to supplying concrete alternative means) no longer meets the needs of builders or the market for this technology. The performance limit of modern cranes, on the contrary, is significantly higher than the values $(5-10 \mathrm{~m} 3 / \mathrm{h})$, usually cited in the literature $[1,9]$, that in the intensification conditions for the monolithic construction, which has been steadily observed for more than 50 years $[5,11,16]$, is an important factor in the leadership of cranes in terms of concrete delivery volumes. These factors also include the high versatility of the working area shape, the minimum requirements for the mobility and non-segregation of the concrete mixture, as well as the lack of alternatives to be present at most of the facilities under construction and reconstruction.

Experience shows that modern belt conveyors (at small angles of their belts inclination) and reciprocating concrete pumps (with strict adherence to the rules of their operation and the use of mixtures of special formulations with an increased content of cement and fine sand fractions) are quite rationally applicable even at much higher values of the cone slump, than earlier (up to 6 and $15 \mathrm{~cm}$, respectively) it was recommended for them [1] and that, unfortunately, is still not obsolete, at the normative level. However, in both cases, the transported mixture stratification significant manifestations absence is unthinkable without the presence of highly effective superplasticizers in it in an individually selected optimal dosage $[12,17,18]$. Pneumatic concrete pumps, although they are suitable for working with 
highly mobile mixtures, nevertheless, in all respects are inferior in this to auger concrete pumps, which in recent decades have strongly displaced pneumatic transport in this competitive area, and therefore it was reoriented mainly to the mixtures of medium mobility. In general, screw concrete pumps should be considered very promising means of mechanization, because they efficiently pump mixtures with increased structural viscosity, especially characteristic of the currently widely used formulations with modifiers based on polycarboxylate esters. It is also noteworthy that such concrete pumps, along with rotary ones, excluded, however, due to low reliability from our consideration, to a lesser extent than others, are subject to the risk of "plugs" in the concrete pipeline due to the possibility of reversing the mixture flow in it.

Analysis of the data collected in the course of the study, as well as its main results presented above, gives us a reason to state the poor consistency of the practice of using many modern means of in-site transportation of concrete mixture with their capabilities. On the one hand, cranes and concrete pumps, whose total share in Russia alone accounts for an average of $90 \%$ of the annual volume of concrete delivery, are used, as a rule, with very low utilization rates of their capacities. On the other hand, there is a number of rarely used mechanization means, which, not differing in the high resource intensity of the realized moving actions and especially strict requirements for the non-segregation of the mixture, with the same mobility in many cases, are able to successfully compete with cranes and concrete pumps in terms of the geometry of working zones and productivity. First of all, this applies to the belt conveyors based on concrete mixer trucks and self-propelled concrete pavers, as well as to means of small mechanization, inertial effect on the mixture, which, for example, is typical for vibrating chutes (this effect is additional for them) and full-fledged inertial conveyors.

\section{Conclusion}

The proposed typology of methods for concrete mix in-site transportation, as well as the presented graphically refined information about the possibilities and areas of mechanization corresponding modern means rational use, can not only somewhat facilitate construction design in terms of justifying the choice of such methods and means, but also help in identifying their shortcomings as well as promising directions and mechanisms for improvement, to a certain extent taking into account the transported material properties.

The obtained results of the study testify in favor of the need to reduce the crane and concrete pumping equipment share in the volumes of monolithic concrete delivery to the place of laying, especially if it is not very far (up to 10-40 m) from the parking lot of the concrete vehicle, which, by the way, is most often the case in practice, since it has been established that, for example, of the total volume of monolithic structures erected annually in Russia, the share of only one foundation construction accounts for at least $45 \%$. At the same time, preliminary implementation of an objective systematic assessment of the competing organizational and technological solutions' effectiveness will give a possibility for the design resources considerable volumes release due to wider use of both small mechanization means, the underestimation of which, by the way, was noted by other researchers [19], and mechanization options based on self-propelled concrete pavers and concrete mixer trucks, equipped with custom-designed concrete-dispensing inertial conveyor equipment.

\section{References}

1. A.A. Afanas'yev, Constructing of monolithic reinforced concrete buildings and engineering structures (Stroyizdat, Moscow, 1990) 
2. S.G. Osmanov, Proceedings of Rostov State University of Civil Engineering 15, 368-369 (2011)

3. B.V. Zhadanovskiy, S.A. Sinenko, Science Review 9 (2), 435-438 (2014)

4. B.M. Yerakhtin, Experience in the construction of hydroengineering complexes (Energoatomizdat, Moscow, 1987)

5. Yu.G. Khayutin, Monolithic concrete: technology of works execution (Stroyizdat, Moscow, 1991)

6. L.M. Kolchedantsev, S.V. Volkov, Housing Construction 11, 21-26 (2015)

7. D.G. Proverbs, P.O. Olomolaiye, F.C. Harris, Building and Environment 31 (4), 363-374 (1996).

8. G.Ya. Bulatov, Magazine of Civil Engineering 1, 32-39 (2009)

9. Ya.G. Mogilevskiy, I.G. Sovalov, A.L. Kopelevich, Machines and equipment for concrete and reinforced concrete works (Stroyizdat, Moscow, 1993)

10. M.V. Komarinskiy, Construction of Unique Buildings and Structures 6, 43-49 (2013)

11. S.A. Ambartsumyan, A.S. Martirosyan, A.V. Galumyan, Industrial and Civil Engineering 2, 29-30 (2010)

12. Yu.G. Barabanshchikov, K.V. Semenov, Power Technology and Engineering 4, 197-200 (2007)

13. S.G. Osmanov, A.L. Zholobov, Bulletin of Civil Engineers 4, 138-145 (2012)

14. S.G. Osmanov, Bulletin of Civil Engineers 2, 128-134 (2018)

15. S.G. Osmanov, Solid State Phenomena 265, 97-102 (2017)

16. S.M. Trembitskiy, L.N. Bekker, P.G. Kebadze, Concrete and Reinforced Concrete 5, 8-11 (2008)

17. M.V. Komarinskiy, R.V. Oniskovets, O.A. Ostarkova, Construction of Unique Buildings and Structures 2 29-41 (2017)

18. L.I. Kastornykh, A.V. Kaklyugin, M.A. Gikalo, I.V. Trishchenko, Construction Materials 3, 4-11 (2020)

19. B.V. Zhadanovskiy, Science Review 21, 342-345 (2015) 